disorders like hysteria, hypochondriasis and neurasthenia, and was then adopted and immortalised by Sigmund Freud and the infant school of psychoanalysis at the beginning of this century.

The Royal College of Physicians of Edinburgh held a two day symposium, on 24 and 25 August 1990 , to mark the bicentenary of Cullen's death. A series of ten lectures were given over the two days by distinguished medical historians from the United States, Canada and England and by members of the Edinburgh College of Physicians and the Edinburgh Medical School. They covered many different aspects of Cullen's career and the development and influence of Edinburgh medicine in the 18th century, and despite being held in the middle of the Edinburgh Festival and the holiday season the symposium was remarkably well attended. It was also fascinating to observe the contrast between the professional historians and the doctors. The latter were largely concerned with Cullen's ideas and teaching in relation to contemporary medicine, the developments he anticipated and those he failed to anticipate. The historians, on the other hand, were more concerned with the broader social and political climate in which Cullen was operating and the medical school developing then but the two approaches complemented one another very well. There was also a well laid out exhibition of books,

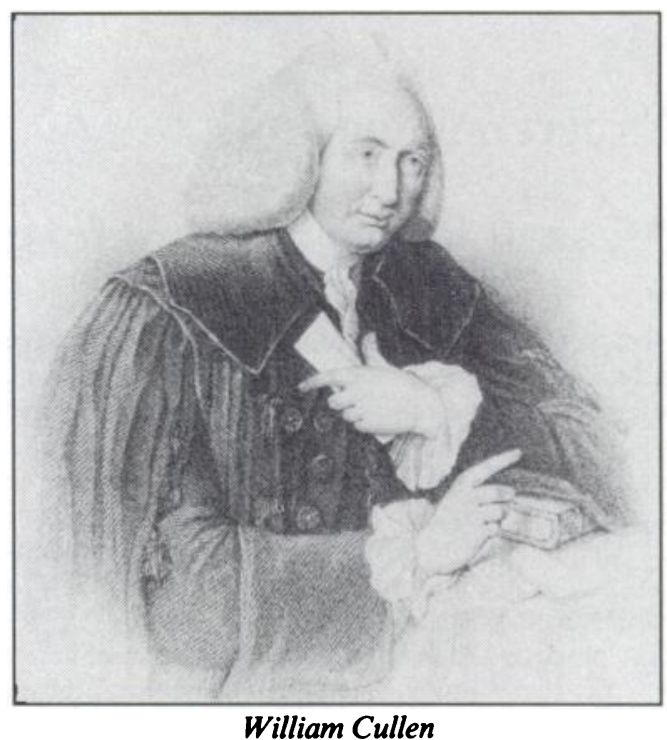

documents and engravingsillustrating Cullen'scareer and the early years of the medical school and the Royal Infirmary which was open to the public throughout the week.

\title{
The application of resource management in the Special Hospitals Service Authority
}

\section{A pilot study at Rampton Hospital}

The Special Hospitals Service Authority (SHSA) has commissed KPMG Peat Marwick McLintock Management Consultants to lead a pilot study to identify how the application of resource management (RM) techniques can best be introduced to the overall benefit of the management of a Special Hospital. The study is to be based at Rampton Hospital. The KPMG staff will work closely with a Project Team comprised of the hospital's staff.

The initiatives associated with the introduction of RM within the NHS have, to date, largely been concentrated in the acute hospital sector, initially at selected pilot sites and currently through the 'rollout' programme supported by the RM Directorate. However, the SHSA feels that, given the objectives, there is no reason to suppose that the Special Hospitals Service cannot benefit from participating in this initiative providing that its unique circumstances are fully appreciated. However, this study could lead the way for the development of RM in psychiatric services in general.

Roger Hinton, Capital Resources Manager at the SHSA says, "The investigation of RM techniques is one of a portfolio of management initiatives being introduced to our Hospitals. Peat's experience in the RM field and the changes being effected by Diana Dickens the UGM and her team combine to create an excellent environment for the study".

For further information contact Charles Kaye, Chief Executive or Roger Hinton at the SHSA (telephone 071609 9700); Barrie Woodcock (Partner) or Jane Finlan, KPMG Birmingham (telephone 021233 1666); Dr Diana Dickens, Rampton Hospital (telephone 0777 84321). 